\title{
Technological innovation in cardiothoracic surgery: A pragmatist's approach
}

\author{
Pedro J. del Nido, MD
}

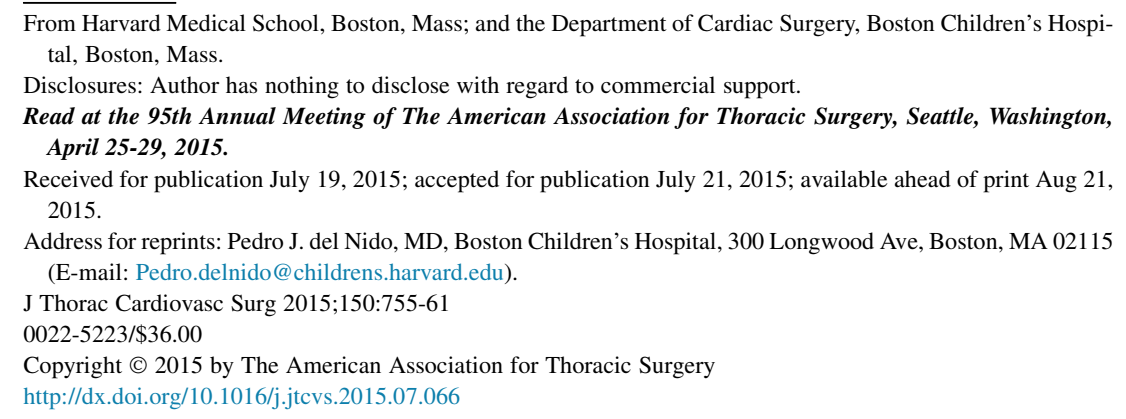

Thank you Dr Coselli for the kind and generous introduction. It was a short year ago when I had the opportunity to stand on this podium to introduce our then president, Dr Sugarbaker, that it became very obvious to me the great responsibility and expectations that came with the role of president. The American Association for Thoracic Surgery (AATS) has a long tradition of providing the forum where the most innovative and significant concepts and treatments for patients with cardiothoracic disease are discussed, evaluated, and disseminated. Because of this tradition, it is the daunting task of the president to maintain the highest standards for all the activities of the Association. Fortunately, it is the greatest strength of this organization that it can count on the work and intellectual input from some of the brightest, most dedicated, and accomplished individuals in our field.

I stand here today feeling extremely fortunate to have had the opportunity to serve the Association and its membership. I am also extremely fortunate to have the support of my family, friends, and colleagues as I have pursued my career as a cardiothoracic surgeon. First and foremost, I would like to express my love and gratitude to my family. My 4 children, Alexander, Sara, Daniel, and Elizabeth, all of whom have made me extremely proud and are the sunshine of life. My love also goes to my daughter-in-law Erika, soon-to-be son-in-law Ryan, and the latest addition to the del Nido family, my grandson Matthew, whose daily picture I receive by text message keeps reminding me of the important things in life. At the center of this very busy family is my wife of 32 years, Martha, who not only is the bedrock of the family but also has helped us all with her wisdom and counsel as we have faced the many challenges in our lives. It is to Martha, who insisted that I pursue my passion for congenital cardiac surgery despite the many uncertainties, that I owe the most respect, love, and admiration.

I would also like to express my deep gratitude to my colleagues at Boston Children's Hospital, including the

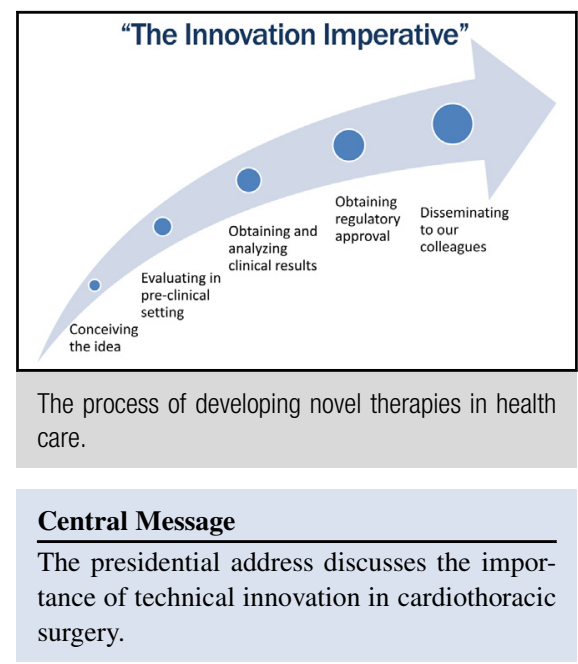

surgical faculty Drs Mayer, Pigula, Fynn-Thompson, Emani, Nathan, Baird, Kaza, and Quinonez. The accomplishments of our program are mainly due to their creative energy and dedication. In particular, I would like to thank John Mayer for his friendship and wise counsel, and my assistant Marlena Sanchez and office manager Janet Horgan for taking up the onerous task of keeping me on track and on task.

My professional career has also benefited from a series of fortunate encounters with individuals who have served as my role models and as mentors. Our past president, Tirone David, was my first attending surgeon as I left the research laboratory to reenter the clinical world. Tirone instilled in me the value of technical precision, attention to detail, and self-assessment and constant analysis of results as a method for improvement. Sidney Levitsky, past president of the Society of Thoracic Surgeons, gave me my first opportunity to practice pediatric cardiac surgery, but, more important, Sidney showed me how it was possible to maintain an active research career while building a clinical practice. Irving Kron, also past president of this Association, mentored me through my first National Institutes of Health (NIH) grant application, helping me take a poorly written and not well thought through discourse and turn it into a scientific proposal. Irv, your career defines mentorship. There are many other individuals who have served as role models for me, too numerous for me to mention. However, relevant to today's topic, I would like to point out one individual whose contributions to this Association 
and vision have helped shape it into the academic organization that it is today. Timothy Gardner, in his presidential address to this Association in 2002, ${ }^{1}$ announced a new initiative to create a committee charged with keeping the Association "focused on its research and development mission." That committee has evolved into the Scientific Affairs and Government Relations Committee led by Irv Kron and now David Jones. The Scientific Affairs and Government Relations Committee has advocated and successfully promoted cardiothoracic surgical research. They have achieved this by insisting on having cardiothoracic surgical representation within the grant review committees of NIH and obtaining NIH support for cardiothoracic surgical translational and clinical research programs, including the Clinical Trials Networks that are generating new knowledge through multicenter trials. The leadership of Tim Gardner and Irv Kron in these efforts serves as an example to us all as to how much impact a single or small group of dedicated individuals can have on the future of our profession. They have reminded us that the mission of the AATS is to "promote scholarship, innovation, and leadership in thoracic and cardiovascular surgery."

To this end, it is with great pleasure that I can report to you today that the Association has reached new milestones in the pursuit of its mission. Through the work of the Scientific Affairs and Government Relations Committee, cardiothoracic surgery has achieved one of the highest levels of representation within the Study Sections of NIH in the committee's history, including cardiothoracic surgical representation at both the Center for Scientific Review and now finally within the review panels of the National Cancer Institute. Although much work still needs to be done, we can take great pride in these accomplishments along with the successes of the Cardiac Surgery Clinical Trials Network and Pediatric Heart Network.

Through the work of the Education Committee, the many individuals who volunteer their time and energy in the Program Committee, and the leaders of our specialty that organize highly successful, specialized courses, such as the Mitral Conclave, Aortic Symposium, Heart Valve Summit, and Focus Course, we can say that the Association has established a leadership role in cardiothoracic surgical education, bringing the latest advances in science, technology, and our surgical craft to our membership and our colleagues. The breadth and depth of these symposia are unprecedented in the history of our Association. The Leadership Academy, started and led by Fred Crawford, continues to provide a focused and intensive course for potential future leaders in our specialty, exposing them to the administrative, interpersonal, and mentoring skills necessary to serve in a leadership position within their institution.

Finally, through the work and tireless efforts of our past president, Dr David Sugarbaker, along with the governing board members who volunteer their time, the AATS Graham Foundation, whose mission it is to drive leadership, learning, and innovation in the pursuit of excellence, has been able to greatly expand its scope providing opportunities to residents, fellows, and young faculty in our specialty. The AATS Graham Foundation enables our trainees and students to attend specialized courses, participate in the Resident Poster Competition, obtain Summer Intern Scholarships, and receive complimentary subscriptions to all the 4 journals of the Association. Furthermore, the Graham Foundation continues to offer alternative funding opportunities for young investigators to develop their research programs through seed and early career grants. Indeed, many of the members of the Scientific Affairs and Government Relations Committee were recipients of grant or fellowship support from the Graham Foundation. In the past year, in partnership with leaders in industry, the Graham Foundation has begun to offer specialized fellowships in fields such as esophageal, arrhythmia, and robotic surgery and has plans for several other similar opportunities for our Fellows and young faculty. This is indeed a very exciting time for our specialty and our Association, but the AATS has not achieved the high status that it enjoys today by resting on its laurels or focusing on its past achievements. Indeed, it is in the genetic makeup of our specialty to look to the future and embrace the challenges that face us.

Today, while our specialty enjoys its well-deserved status as innovative and forward thinking, there is the constant danger that we become complacent and accepting of current standards and current therapies, so much so that we stop asking ourselves the question, "How can we do better?"

In his presidential address to this Association, given at the turn of this millennium, Dr Delos Cosgrove talked about the "Innovation Imperative.", Toby warned that he had detected a gradual but real change in our attitudes toward new technology with the excitement for it being replaced with suspicion. He expressed concern that we had become slow adopters of new technology and hesitant to innovate. The possible explanations for this change he thought could be that we were victims of our own success; that our education and training programs focused on accumulation of information and gave less emphasis on acquisition of new knowledge through investigation; and that societal pressures to reduce the cost of health care made us wary of change and innovative therapies. He went on to say that we must think anew in education, research, and health care delivery. He pointed out that innovation had to occur, in the way we acquire new skills and keep up with the constant influx of new medical knowledge, in the way that we conduct clinical research, because this is the bottleneck between new discoveries and their application to the patients, and innovation had to occur in the way we think about health care delivery, moving away from quantity as the 
major metric of our achievements to quality of outcomes and value. However, it is my belief that at the core of medical innovation, that which has had the greatest impact is innovative technology. Technological advances have been the major driver for our increase in life expectancy and our ability to treat complex medical conditions that our predecessors could only palliate. In many ways, innovative medical technology has been vital to the advance of our specialty.

Cardiothoracic surgeons have been inventors, developers, modifiers, and in general early adopters of a wide range of technologies from medical devices, such as heart valves, bypass machines, blood vessel substitutes, novel imaging techniques, and even to application of the new knowledge of the human genome to our surgical practice. The examples from our past are many, including the accomplishments of pioneers such as Robert Gross, C. Walton Lillehei, Albert Starr, Rene Favaloro, and Michael Debakey to name just a few in cardiac surgery, and our own Evarts Graham, Ronald Belsey, and Hermes Grillo to name a few in thoracic surgery. These individuals, in part because of their vision, scientific discipline, and great technical skill, were able to change the practice of our specialty in fundamental ways. But most of all, they benefited from the recognition that the best way to generate new knowledge was to put their theories into practice and assess their benefit, or not, through their practice. This fundamentally pragmatic approach or method is characteristic of our pioneers and indeed of our specialty.

Earlier this year at the annual meeting of the Society of Thoracic Surgeons, I had the privilege of delivering the Ferguson Lecture, which offers an opportunity for the presenter to reflect on and analyze the major challenges facing our profession at the present time. I discussed how the concept of pragmatism as described by the Pragmatist Philosophical School had served our profession so well for over a century. The Pragmatist School and its leading thinker, Williams James, proposed that real knowledge comes from the method of taking a theory and applying in the real world, assessing the results, and accepting or discarding the theory on the basis of these results. To phrase this differently, he proposed that to obtain practical knowledge, we should ask ourselves:

"What definite difference it will make to you and me, at definite instants of our life, if this world-formula or that world-formula be the true one" 3

"Theories thus become instruments, not answers to enigmas, in which we can rest." 3

Thus, the meaning of an idea can be found by its practical consequences. Furthermore, no matter which great authority proposes a particular theory, if it does not fit the facts, then it should soon be discarded. The great pragmatist philosopher William James stated "A pragmatist turns his back resolutely ... from abstraction and insufficiency, from verbal solutions, from bad a priori reasons, from fixed principles, closed systems, and pretended absolutes ...," "it (pragmatism) does not stand for any special results. It is a method only." 3

At around the same time period, in the world of surgery, similar tenets to those of the early pragmatist philosophers were being formed. At the end of the 19th century, Theodor Billroth introduced the concept of surgeons tracking their techniques and their results, good or bad. He proposed that an honest discussion of morbidity and mortality was the best method for advancing our knowledge in surgery. This was a radical concept at the time that he proposed it. This tenet was also carried by William Halstead to America in setting up the first surgical residency program at the Johns Hopkins Hospital. The importance of this philosophical approach to the advancement of our specialty and advancement of medicine in general cannot be understated. It is the basis by which we assess the value of our current knowledge and acquire new knowledge. The pragmatist approach leaves us open to new ideas and new solutions to problems that may be better than the old solutions. This mindset is at the core of innovation. It drives the innovator's desire for generating better solutions and the willingness to try something new not for the sake of novelty, but for a better result.

I contend that the relentless advance of technology and new concepts in our specialty over the past 50 to 70 years is largely a result of our approach to innovation that exemplifies the tenets of the pragmatist philosophy. The explosion of novel surgical procedures and development of new devices that occurred in our specialty from the 1930s to the 1970s occurred as a direct result of this pragmatist approach to new theories and new concepts. This was a time when a surgeon would go to the animal laboratory, develop a procedure or a new device, and then directly apply it in the clinical setting and evaluate the outcomes, good or bad, very much as Billroth proposed. The first closed heart operations, such as ligation of a patent arterial duct, resection and repair of coarctation, and creation of an aortopulmonary shunt to treat blue babies, were developed, tested, and disseminated this way.

At times, partnerships were created between surgeons and engineers to develop new devices, resulting in the first pacemakers, the first batteries for portable and implantable pacemakers, and the first mechanical valves to replace diseased and dysfunctional valves in the heart (Figure 1). Some of these partnerships led to the creation of new companies not only to mass produce the devices but also to further refine and improve them. At times, individual surgeons through their own initiatives, led to the development of novel concepts such as artificial blood vessels, which 


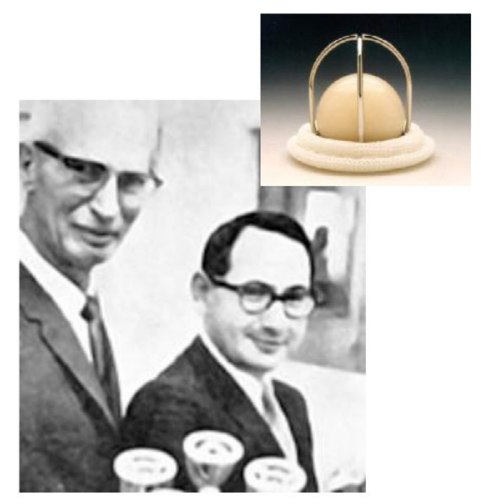

Starr and Edwards

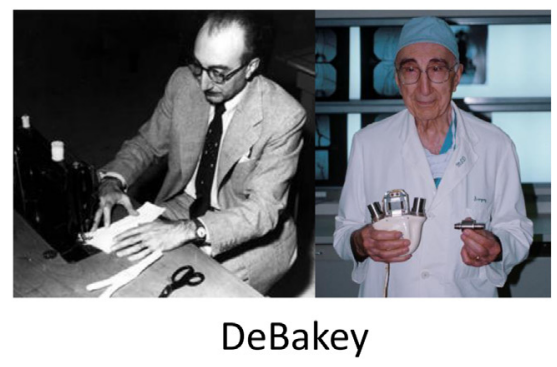

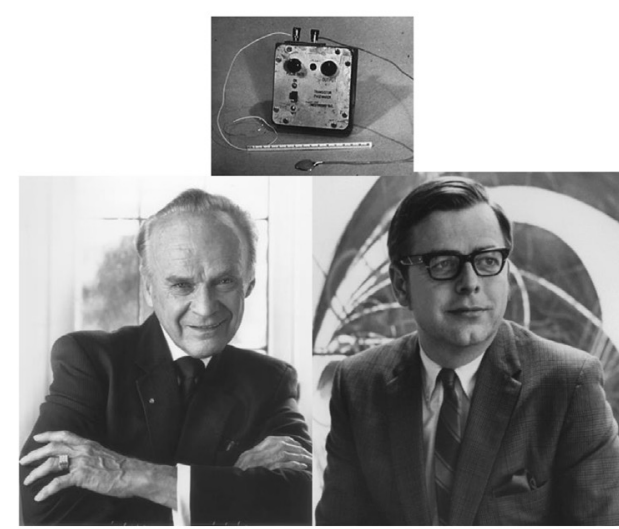

Lillehei and Bakken

FIGURE 1. Pioneers in cardiovascular surgery device development.

subsequently resulted in the creation of entire new industries. Indeed, many of the corporate names displayed in our exhibit hall today represent companies that came into being as a result of the interaction and collaboration between surgeons in our specialty and engineers, scientists, and corporate leaders. These partnerships benefited our patients, because new treatments could be applied and disseminated more rapidly; they benefited the industry because they provided a critical revenue stream for a company's survival and benefited cardiothoracic surgeons because they gave us new ways to treat some of the most deadly diseases of our time and increased the demand for our specialty.

For the field of cardiothoracic surgery, the period from the 1930s to the 1970s represented one of the most rapidly changing and most exciting times, similar to what occurred in the semiconductor world from the 1960s to now. One could characterize this period as following Moore's Law for transistors, which predicted an exponential increase in transistor density over time, but for cardiothoracic surgery. We saw everything from roller pumps to oxygenators, prosthetic heart valves, to artificial hearts conceived, tested, applied, and disseminated at a pace that was unprecedented (Figure 2). But these are the success stories. We don't often recount the concepts that failed and were discarded and the consequences of these experiments for our patients.
Nevertheless, both the successes and the failures resulted from our pragmatist approach to acquiring new knowledge, what we now popularly term "innovation." Then, in 1976, Congress passed the Medical Device amendment to the Federal Food, Drug, and Cosmetic Act, expanding the authority of the Food and Drug Administration and requiring that all medical devices be classified into 3 classes depending on the risk involved to the patient. Furthermore, based on the level of risk, the act required that a review process be developed for approval before marketing the device. Thus, not only were good manufacturing standards required for medical devices to be used in the clinical setting but also strict standards for safety and efficacy were to be applied before the approval of new devices. The result of this expansion of regulatory oversight was that a more uniform bar was created for new technologies before they could be applied broadly in the clinic and added a level of structure to the process of medical innovation.

Although this new act of Congress had a major impact on industry, for the cardiothoracic surgical community at large, the impact of the Medical Device Amendment of 1976 at first was minimal, because the growth of surgical volume was almost exponential during the decades of the 1980s and 1990s, as the coronary artery bypass grafting (red) line shows in Figure 3. ${ }^{4}$ The rapidly expanding application of already developed procedures, such as coronary bypass 

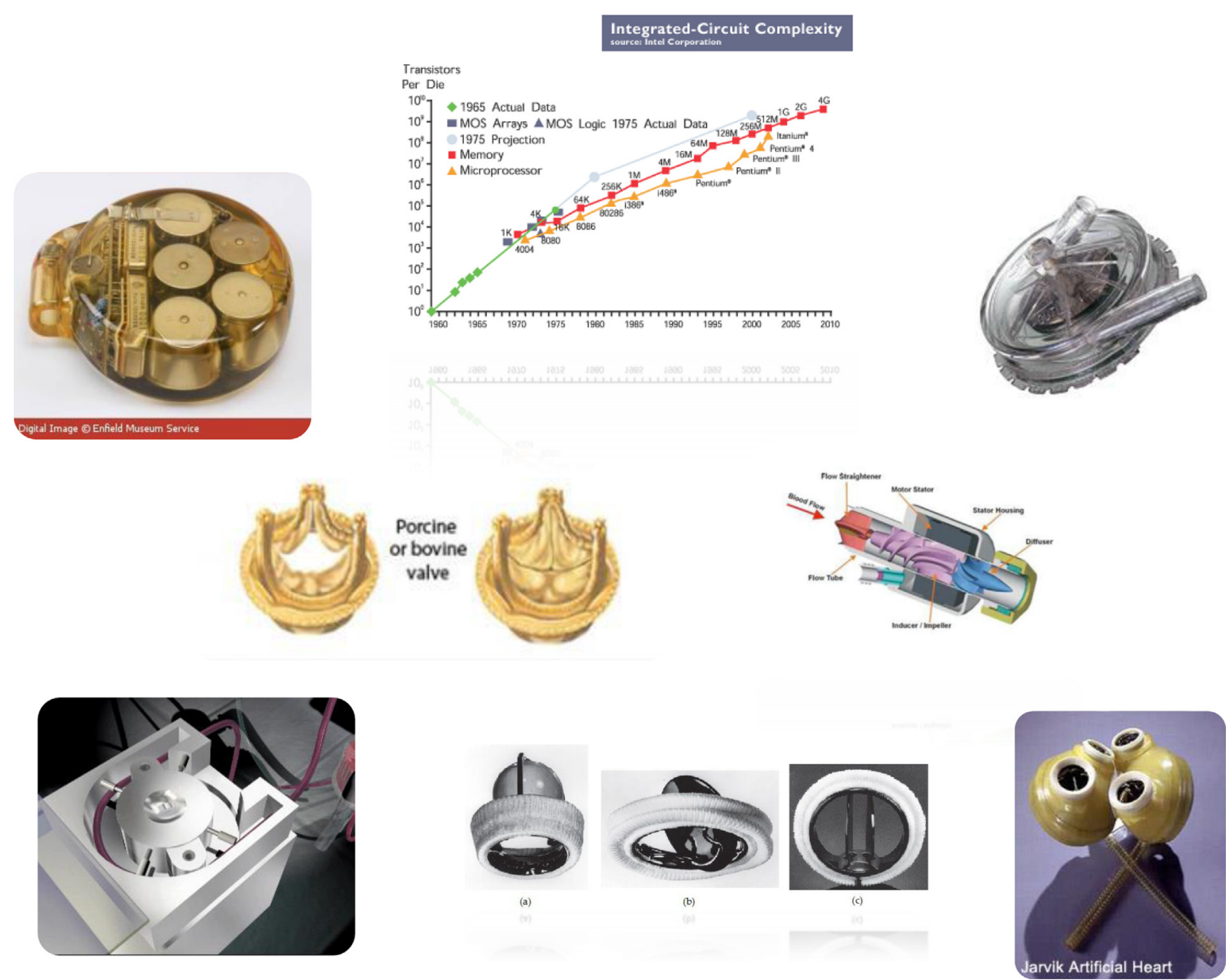

FIGURE 2. Medical devices that had a major impact in cardiovascular surgery. From left to bottom right: pacemaker, centrifugal pump, bioprosthetic valves, continuous-flow turbine pumps, roller pump, mechanical valves, and total artificial heart.

grafting, heart valve replacement surgery, and thoracic organ resection and reconstruction procedures, ensured that the demand for cardiothoracic surgical specialists was high. In some cases, this high demand led to a level of complacency that Dr Cosgrove warned us about during his presidential address to this Association in the year 2000. In that address, Toby warned of all the challenges that our specialty was facing at the time, including greater competition from our cardiology colleagues armed with alternative technology, as is shown by the percutaneous coronary intervention (green) line in Figure 3, with the growth of percutaneous catheter interventions, greater regulatory oversight of new technology, reallocation of resources away from surgical specialties, and lower reimbursement for surgical procedures. Many of these same pressures on our specialty are present today. But Toby also proposed that the response to these challenges must be a resolute commitment to fostering innovation, what he called the "Innovation Imperative."
Today, the process of bringing technological advances to our patients has become more structured. As a consequence of the regulatory and financial pressures on the health care environment, the process of developing a novel therapy has become more complex. The steps of conceiving the idea, evaluating it in the preclinical setting, obtaining and analyzing initial clinical results, obtaining regulatory approval, and disseminating it to our colleagues (Figure 4) often require extensive resources and knowhow that are not readily available to the practicing surgeon. However, this does not mean that we should take a passive approach and wait for new technology or new therapies to reach us. History has shown us that a passive approach will virtually guarantee our obsolescence. Instead we must recognize that the process is complex, and just as we have in the past, we must look for ways to generate and advance our ideas. As in the past, this will require that we forge partnerships with others outside our field, whether they are engineers, basic scientists, and increasingly, 


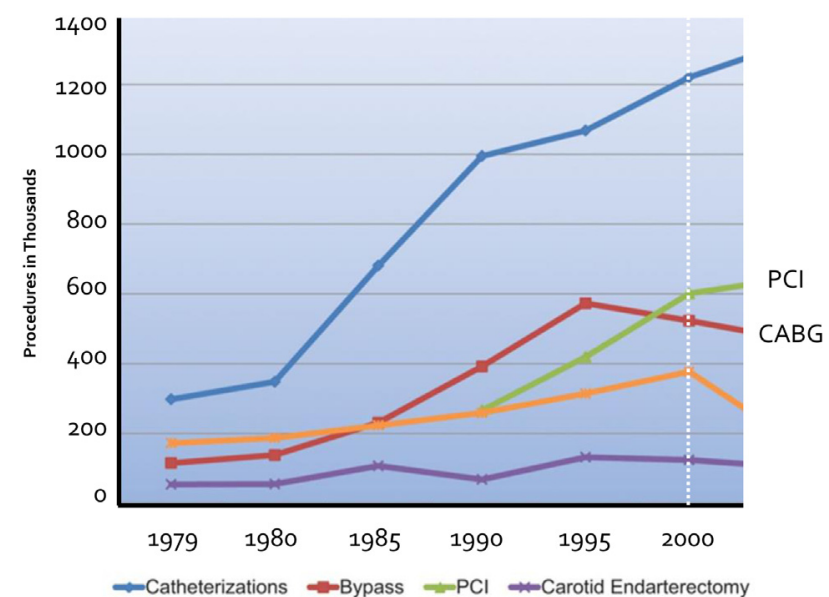

FIGURE 3. Trends in cardiovascular procedures, United States: 1979 to 2010. From Go AS, Mozaffarian D, Roger VL, Benjamin EJ, Berry JD, Blaha MJ, et al. Circulation. 2014;129:e28-e292; page e278. CABG, Coronary artery bypass grafting; $P C I$, percutaneous coronary intervention.

partnerships with experts in public policy, regulatory matters, and commercialization. In the past, we have treated partnerships with those outside the medical or scientific fields with aversion, as if they were the third rail. However, when we have ventured into these partnerships, we have discovered ways to work together to achieve a common goal, which has often been of benefit to our patients, to our specialty, and to society at large. There are now many examples of cardiothoracic surgeons not only working alongside but also at times becoming policy makers and regulators themselves. Many of these individuals are members of this very Association. Furthermore, many of us have built our academic careers on the basis of the creativity and productivity generated by partnerships not only with basic scientists and engineers but also with industry colleagues.

The NIH recognized the potential benefit of these collaborations when it set up the Bioengineering Research Partnership funding mechanism, which allowed academics in medicine and engineering to work together with researchers within industry to tackle large and complex medical problems. I was the beneficiary of a couple of these grants from the NIH, and several discoveries were the product of these projects. Of course, these discoveries must still be disseminated to our colleagues via presentations at professional meetings and journal publications. Also, we must accept that these discoveries belong to the institution where they were generated, because that is the covenant that we agree to when we choose to work in an academic institution. However, the major benefits of these partnerships include a greater focus on practical patient application of the discovery and access to the technology, regulatory, and commercialization resources of industry, which are often not available in an academic laboratory.

I recognize that this model of collaboration has its limitations, but there are other alternatives to advance an individual investigator's idea to the clinic. These include organizing your own structure or company in collaboration with individuals who have the expertise in the regulatory and business domains that you may be lacking. These are but examples of how you can bring your idea from the concept stage to the patient. However, the most important

\section{"The Innovation Imperative"}

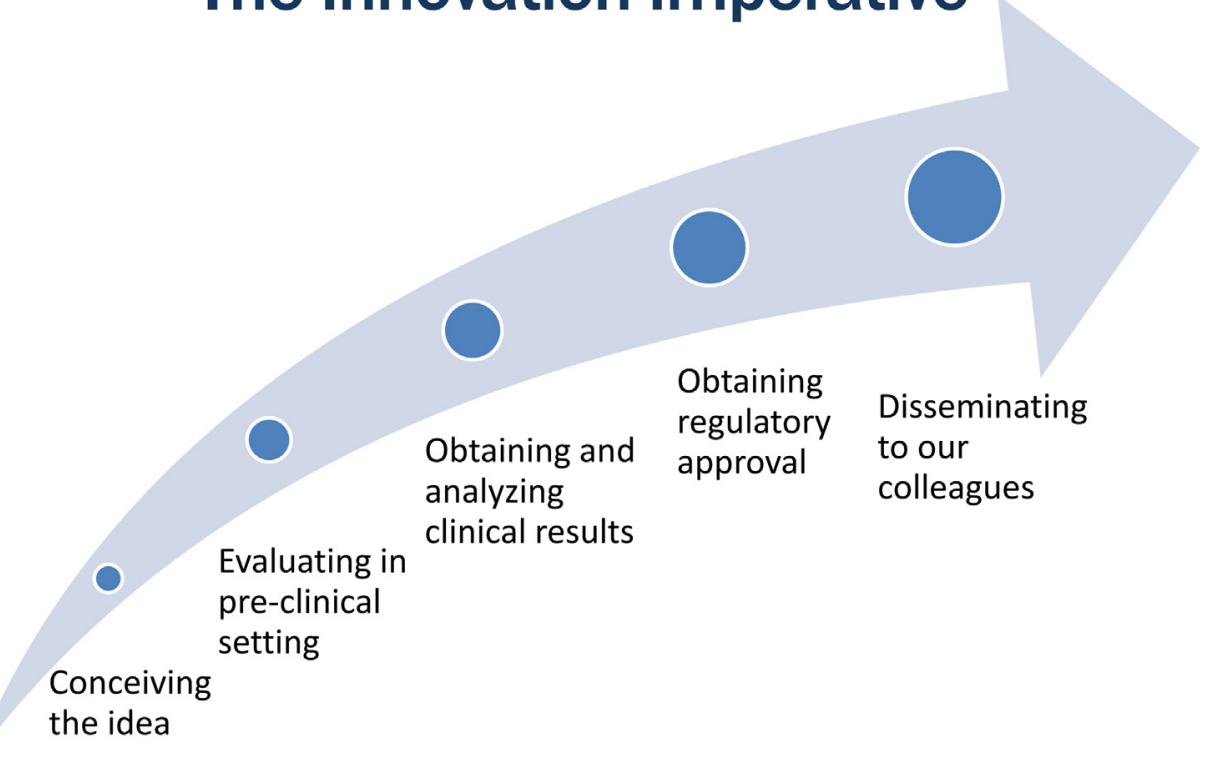

FIGURE 4. The process of developing novel therapies in health care. 
message is that you recognize the complexity of doing so in today's environment, and that you prepare for it, both by gaining an understanding of this process and by exhibiting the same determination that got you through your cardiothoracic training and indeed your career. The potential reward for these efforts is that your idea may ultimately benefit far more patients than you could by treating them yourself directly. As for most of us, however, the opportunity to advance an important new concept or novel technology will come in the form of a new device or new therapy that has already been developed past preclinical evaluation. We may have the opportunity to participate in its clinical evaluation. This also will require that we devote the time and energy to understand the new technology to the point where we are comfortable applying it and the discipline to adhere to the scientific protocol developed to test it. Here again, the rewards will come from both your application of this new technology to your patient and knowing that you have accelerated the process of medical technology evaluation, which is critical to its safe application.

But, it is not just the individual practitioner or researcher who can contribute to the process of bringing new technology to the clinic. Our professional associations also can participate in this process. Indeed, they must. Our professional organizations have already learned to engage government regulators and policy makers, not only serving to represent individual members but also providing a more powerful voice for our specialty. They have been able to do this without losing sight of their ultimate goal—to help our patients-or their mission. But if we are to advance innovative technology within our field, our professional organizations must also develop ways to engage our industry colleagues. The complexity of the pathway for advancing new technology from the idea stage to safe and effective clinical therapy often requires partnerships with not only technology specialists but also partnerships with specialists in regulatory matters and with industry. The challenge is of course to not lose sight of our goal of improving the lives of our patients and to maintain our pragmatist approach to new theories and new technologies, which is to evaluate ideas through their practice and accept or discard them on the basis of their results. These are the fundamental tenets of the pragmatist school and the tenets that drove the accelerated pace of innovation in our field during the last three quarters of a century.

To this end, I believe that our professional organizations can play a critical role by supporting the activities of our colleagues as they develop technology, evaluate it, and advance it to clinical application. Whether we support young investigators by providing grants or special
Fellowships; whether we advocate for surgical scientists for support from the NIH, Agency for Healthcare Research and Quality, or Food and Drug Administration; whether we promote the development of clinical trial protocols or clinical research Networks such as the Cardiac Surgery Network or the Pediatric Heart Network of the NIH; whether we encourage participation in pivotal trials or Investigational Device Exemption trials; or whether we develop educational programs for our specialty to discuss and disseminate new technology such as the Mitral Conclave and Aortic Symposium, these are all activities that this Association is already doing and must continue to do, to support our specialty in its pursuit of the innovation imperative.

However, as important as these activities are, we must also recognize that we need to do more as an Association and as a profession. We must explore ways that we can partner with industry to ensure that the best innovative ideas of today reach our patients in a safe and timely manner. We must ensure that the cardiothoracic surgical innovators of today have a forum and a support structure for their ideas to be applied, their results to be evaluated, and their ideas advanced. Taking a passive stance on these critical issues is not an option for us lest we risk obsolescence. I firmly believe that the pragmatist philosophy or as some have called it, the pioneering spirit, has not left our specialty. But that pioneering spirit needs nurturing, recognition, and support. If you have any doubts as to whether the innovative spirit and the pragmatist philosophy have left our specialty, I simply ask you to look around you and take in what is being presented at this meeting over these few days. If you do, you will find a wealth of new ideas, jampacked with novel concepts and exciting new technologies. What we now need is for all of us to join forces and reach outside the boundaries of our profession, with a common goal to improve the lives of our patients.

Thank you very much.

You can watch a Webcast of this AATS meeting presentation by going to: http://webcast.aats.org/2015/ Video/Monday/04-27-15_4E_1125_del_Nido.mp4.

\section{References}

1. Gardner TJ. Presidential address: our heritage and our future. J Thorac Cardiovasc Surg. 2002;124:649-54.

2. Cosgrove DM. The innovation imperative. J Thorac Cardiovasc Surg. 2000;120 839-42.

3. Shook JR, ed. The Essential William James. Amherst, NY: Prometheus Books; 2011.

4. Go AS, Mozaffarian D, Roger VL, Benjamin EJ, Berry JD, Blaha MJ, et al. Heart disease and stroke statistics-2014 update: a report from the American Heart Association. Circulation. 2014;129:e28-292. 